\title{
p53 is required for nerve growth factor-mediated differentiation of PC12 cells via regulation of TrkA levels
}

\author{
J Zhang ${ }^{1}$, W Yan ${ }^{1}$ and X Chen ${ }^{*, 1}$ \\ ${ }^{1}$ Department of Cell Biology, The University of Alabama at Birmingham, \\ Birmingham, 1530 3rd Avenue South, AL 35294-0005, USA \\ * Corresponding author: X Chen, Department of Cell Biology, The University of \\ Alabama at Birmingham, 1530 3rd Avenue South, Birmingham, AL 35294- \\ 0005, USA. Tel: + 1-205-975-1798; Fax: + 1-205-934-0950; \\ E-mail: xchen@uab.edu
}

Received 12.12.05; revised 13.4.06; accepted 18.4.06; published online 26.5.06 Edited by L Greene

\begin{abstract}
p53 is necessary for the elimination of neural cells inappropriately differentiated or in response to stimuli. However, the role of p53 in neuronal differentiation is not certain. Here, we showed that nerve growth factor (NGF)mediated differentiation in PC12 cells is enhanced by overexpression of wild-type $\mathrm{p} 53$ but inhibited by mutant p53 or knockdown of endogenous wild-type p53, the latter of which can be rescued by expression of exogenous wild-type p53. Interestingly, p53 knockdown or overexpression of mutant p53 attenuates NGF-mediated activation of TrkA, the high-affinity receptor for NGF and a tyrosine kinase, and activation of the mitogen-activated protein kinase pathway. In addition, p53 knockdown reduces the constitutive levels of TrkA, which renders PC12 cells inert to NGF. And finally, we showed that both constitutive and stimuli-induced expressions of TrkA are regulated by $\mathrm{p} 53$ and that induction of TrkA by activated endogenous p53 enhances NGFmediated differentiation. Taken together, our data demonstrate that p53 plays a critical role in NGF-mediated neuronal differentiation in PC12 cells at least in part via regulation of TrkA levels.
\end{abstract}

Cell Death and Differentiation (2006) 13, 2118-2128. doi:10.1038/sj.cdd.4401972; published online 26 May 2006

Keywords: p53; NGF; TrkA; differentiation; cell cycle

Abbreviations: NGF, nerve growth factor; MAPK, mitogenactivated protein kinase

\section{Introduction}

Nerve growth factor (NGF) ${ }^{1}$ has profound effects on the differentiation and survival of a subset of neurons, ${ }^{2}$ which is primarily studied in PC12 cells, a model system for neuronal differentiation. ${ }^{3}$ Upon exposure to NGF, PC12 cells cease division, extend neurites, and acquire characteristics similar to sympathetic neurons. ${ }^{2}$ This is largely mediated through the binding of NGF to TrkA, the high-affinity NGF receptor, which undergoes dimerization and autophosphorylation and then activates two major pathways: the mitogen-activated protein kinase (MAPK) pathway for neurite outgrowth and the PI3K pathway for neural survival. $^{2}$

p53 transcription factor regulates a diverse array of target genes that mediate tumor suppression by inducing cell cycle arrest and apoptosis. ${ }^{4-6}$ In the nervous system, p53 is essential for the elimination of inappropriately differentiated neural progenitors and for neuronal apoptosis in response to stimuli. ${ }^{7,8}$ p53 may play a role in neuronal differentiation, but current knowledge is controversial. The first implication comes from the observation that some p53-deficient mice developed exencephalic brains. ${ }^{9}$ Later studies showed that p53 expression oscillates in neuronal cells undergoing differentiation $^{10}$ and during development. ${ }^{11}$ In addition, NGF-mediated neuronal differentiation was showed to be inhibited by a dominant-negative form of p53. ${ }^{10,12}$ Furthermore, several p53 target genes, such as p21 and BTG2, play a role in neuronal differentiation. ${ }^{4}$ However, other studies disputed such a role for p53. For example, p53 was found to be necessary for NGF-mediated cell cycle arrest, but not neurite outgrowth ${ }^{13}$ and suppression of p53 was found to enhance, rather than attenuate, neuronal differentiation. ${ }^{14}$ To further address this, we examined the role of p53 in NGF-mediated neuronal differentiation and provided evidence that p53 plays a critical role in NGF-mediated neuronal differentiation at least in part via regulation of TrkA levels.

\section{Results}

\section{Exogenous p53 promotes NGF-mediated neurite outgrowth in PC12 cells}

To investigate the role of p53 in NGF-mediated differentiation, we generated PC12 cell lines that inducibly express HAtagged wild-type murine p53. Multiple clones were selected and two representative clones, which express comparable amounts of p53, were chosen for further studies (Figure 1A). Listed in Table 1 is a brief summary of cell lines used and/or generated in this study. To verify the activity of HA-p53, the level of p21 was examined and found to be induced (Figure 1A). Next, we performed growth rate assay and found that cells failed to proliferate in the presence of p53 (Figure 1B and $\mathrm{C}$ ). Since $\mathrm{p} 53$ overexpression can lead to either cell cycle arrest or apoptosis, it is necessary to make sure that the level of p53 expressed in these cell lines does not induce apoptosis, which would obliterate the effect of p53 on neuronal differentiation. The number of cells with sub-G1 DNA content directly correlates with the degree of cells undergoing apoptosis. Thus, we performed DNA histogram assay and found that upon p53 induction, PC12-HA-p53-46 cells 
A

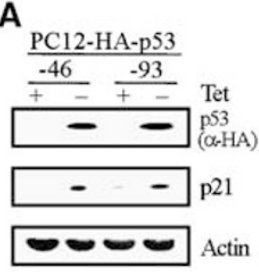

B

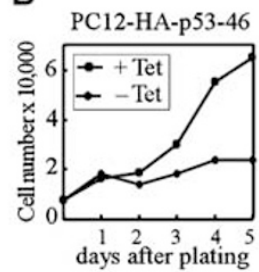

C

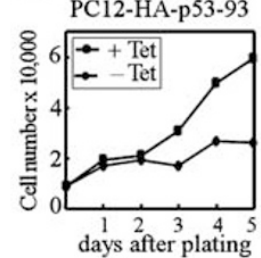

D

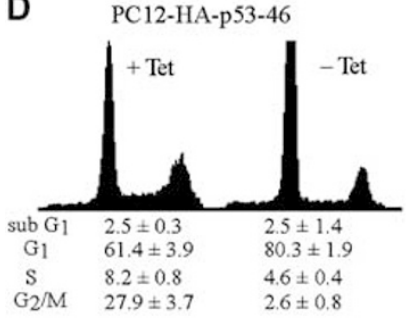

E

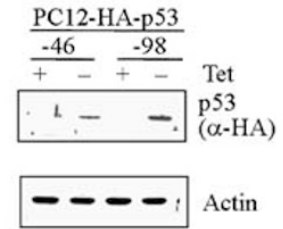

$\mathbf{F}$

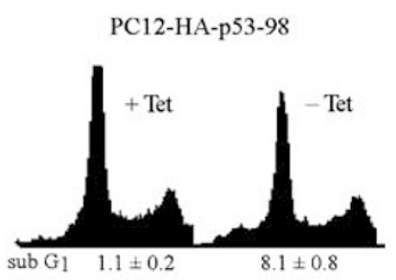

G

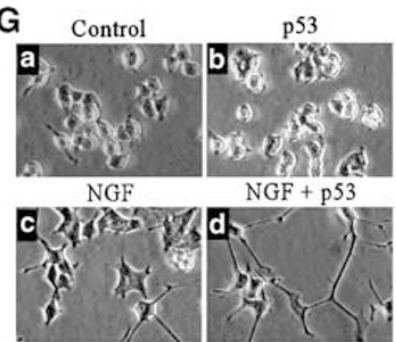

H

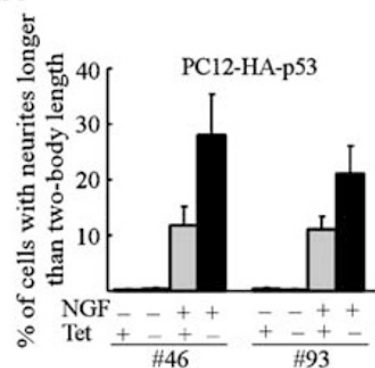

I

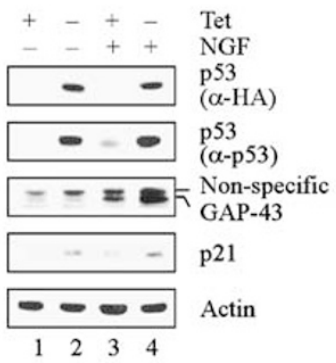

Figure 1 Overexpression of p53 promotes NGF-mediated neurite outgrowth. (A) Generation of PC12 cell lines inducibly expressing wild-type p53. The level of HA-tagged p53, p21, and actin was assayed by Western blot analysis. (B and C) Growth rates of cells in the presence or absence of wild-type p53 over a 5-day period. ( $\mathbf{D}$ and $\mathbf{F}$ ) DNA histogram analysis of PC12 cells in the absence or presence of p53. PC12-HA-p53-46 cells (D) or PC12-HA-p53-98 cells $(\mathbf{F})$ were uninduced or induced to express wild-type p53 for $72 \mathrm{~h}$ and the percentage of cells in each phase of the cell cycle was determined by DNA histogram analysis. DNA content was quantified using the data from at least three independent experiments. (E) The levels of p53 expressed in cells that are capable of inducing cell cycle arrest and apoptosis. PC12 cells were uninduced or induced to express p53 for $24 \mathrm{~h}$ and the levels of HA-tagged murine p53 were examined by Western blot analysis with anti-HA antibody. The levels of actin were quantified and used as a loading control. (G) Representative microscopy images of PC12 cells with or without $\mathrm{p53}$ expression in the presence or absence of NGF. PC12 cells were uninduced ( $a$ and $c$ ) or induced ( $b$ and d) to express p53 for $6 \mathrm{~h}$, and then switched to a $2 \%$ low serum medium and treated with (c and d) or without (a and b) NGF for 3 days. (H) Quantitative analysis of PC12 cells bearing neurites are shown in $(\mathbf{G})$. The percentages of cells with neurites longer than two-body length were calculated. At least 500 cells were counted for each treatment, and the error bars represent the S.D. of triplicate results. (I) Overexpression of p53 induces p21 and GAP-43. PC12-HA-p53-46 cells were treated as describe in $(\mathbf{G})$ and used for Western blot analysis with antibodies against HA, p53, p21, GAP-43, and actin

arrested primarily in G1 (Figure 1D). However, PC12-HA-p5398, which is capable of expressing a higher level of p53 (Figure 1E), underwent apoptosis as the percentage of cells with sub-G1 DNA content increased from 1.1 to $8.1 \%$ upon induction of p53 (Figure 1F).

To test the effect of p53, PC12 cells were uninduced or induced to express p53, followed by NGF treatment for 3 days. The cell morphology was examined by phase-contrast microscopy. We found that NGF treatment was able to induce PC12 cells to undergo differentiation (Figure $1 \mathrm{Gc}$ ) whereas overexpression of p53 alone did not (Figure 1Gb). Interestingly, we observed that upon NGF treatment, PC12 cells with p53 overexpression extended more and longer neurites compared to cells without p53 overexpression (Figure 1Gcd). To confirm this, neurite outgrowth was quantified (Figure $1 \mathrm{H}$ ). Cells with neurites are defined as ones that possess at least one neurite of greater than two-body length and at least 500 cells were assayed in each group. We found that the percentage of cells with neurites longer than two-body length was highly increased by $\mathrm{p} 53$, ranging from 100 to $130 \%$ (Figure $1 \mathrm{H}$ ). Next, we analyzed the expression of p21 and GAP-43. p21 plays a role in NGF-mediated differentiation by inducing cell cycle arrest in $\mathrm{G} 1^{15}$ whereas GAP-43 is a late differentiation marker associated with neurite outgrowth. ${ }^{16}$ As shown in Figure 1l, overexpression of p53 alone induced p21, but not GAP-43 (Figure 1I, lane 2), which might explain why p53 alone cannot induce PC12 cells to differentiate. Upon NGF treatment, endogenous p53 was accumulated accompanied by the induction of p21 and GAP43 (Figure 1l, lane 3). Moreover, the inductions of p21 and GAP-43 by NGF were highly increased upon p53 expression (Figure 1I, compare lanes 3-4). Taken together, these results implied that p53 plays a role in NGF-mediated differentiation in $\mathrm{PC} 12$ cells.

\section{Overexpression of mutant p53 attenuates NGF- mediated neurite outgrowth in PC12 cells}

To further investigate the role of $p 53$, we generated $P C 12$ cell lines that inducibly express HA-tagged murine p53(A135V) (Table 1). This mutant was shown to be dominant negative toward wild-type p53 at the non-permissive temperature $\left(38.5^{\circ} \mathrm{C}\right) .{ }^{17}$ Two representative clones, which are capable of expressing comparable amounts of p53(A135V), were chosen for further studies (Figure 2A). Unlike wild-type p53, p53(A135V) was unable to induce p21 (Figure 2A) and growth suppression at the non-permissive temperature (Figure 2B and $\mathrm{C}$ ). Next, we examined the effect of p53(A135V) on neuronal differentiation and found that upon NGF treatment, the neurites were less and shorter in PC12 cells with p53(A135V) expression than that in control cells as the number of cells with neurites was reduced by $59-68 \%$ upon p53(A135V) expression (Figure $2 \mathrm{D}$ and $\mathrm{E})$. Likewise, the induction of p21 and GAP-43 by NGF was attenuated or almost completely abolished by p53(A135V) (Figure 2F). Similarly, we found that upon treatment with NGF for 6 days, neurite outgrowth was still inhibited by mutant p53(A135V), but the extent of reduction was less profound. 
Table 1 A brief summary of cell lines used

Cell line

\section{PC12}

PC12-HA-p53-46 PC12-HA-p53-80 PC12-HA-p53-93

PC12-HA-p53-98

PC12-HA-p53(A135V)-7

PC12-HA-p53(A135V)-47

PC12-p53KD-62 PC12-p53KD-106

PC12(p53KD)-HA-p53-28

PC12(p53KD)-HA-p53-64

SH-SY5Y

SH-SY5Y-HA-p53-7

SH-SY5Y-HA-p53-9

H1299-HA-p53-15

\section{Definition}

Rat neuron-like pheochromocytoma cell line

PC12 cell lines that can inducibly express HA-tagged murine wild-type p53 under the control of the tetracycline-repressible (Tet-off) promoter.

PC12 cell lines that can inducibly express HA-tagged murine mutant p53(A135V) under the control of the tetracycline-repressible (Tet-off) promoter.

PC12 cell lines in which endogenous p53 is knocked down by siRNA.

PC12 cell lines in which endogenous p53 is knocked down by siRNA and HA-tagged murine wild-type p53 can be inducibly expressed under the control of the tetracycline-repressible (Tet-off) promoter.

Human neuroblastoma cell line

SH-SY5Y cell lines that can inducibly express HA-tagged human wild-type p53 under the control of the tetracycline-inducible (Tet-on) promoter.

Human lung carcinoma $\mathrm{H} 1299$ cell line that can inducibly express HA-tagged human wild-type p53 under the control of the tetracycline-repressible (Tet-off) promoter
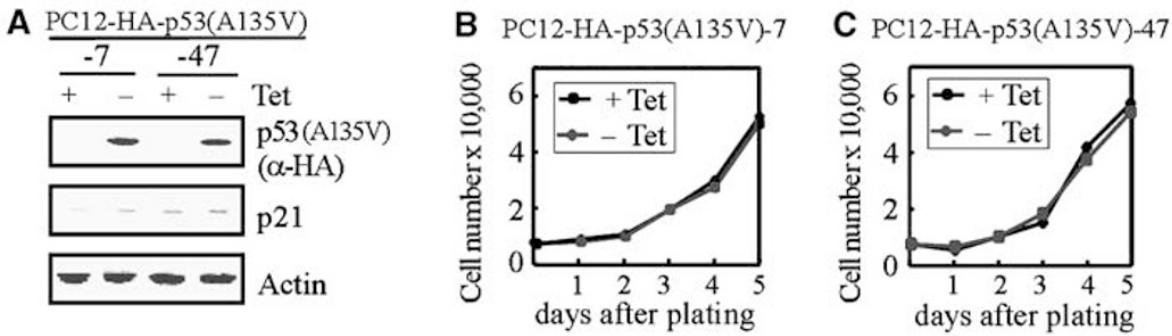

D
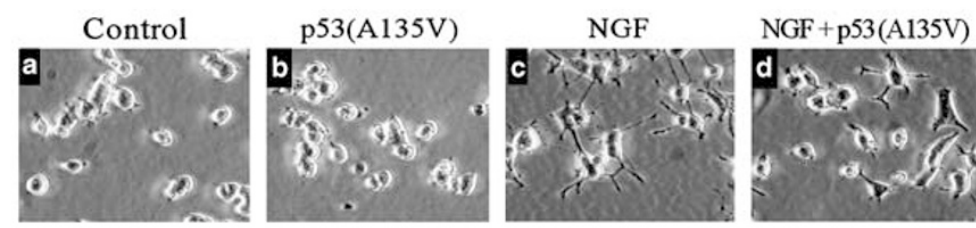

E

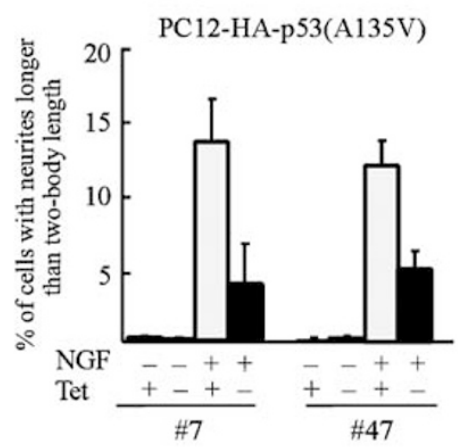

$\mathbf{F}$

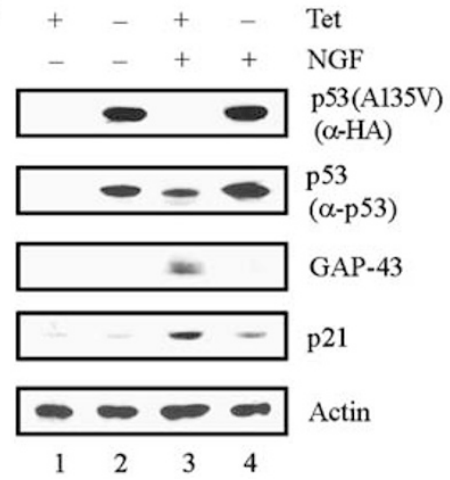

Figure 2 Overexpression of mutant p53(A135V) attenuates NGF-mediated neurite outgrowth. (A) Establishment of stable PC12 cell lines inducibly expressing p53(A135V). The level of HA-tagged p53(A135V), p21, and actin was assayed by Western blot analysis with antibodies against HA, p21, and actin. (B and C) Growth rates of cells in the presence or absence of p53(A135V) over a 5-day period. (D) Representative microscopy images of PC12 cells with or without p53(A135V) expression in the presence or absence of NGF. PC12-HA-p53(A135V)-7 cells were uninduced (a and c) or induced (b and d) to express p53(A135V) for 16 h and then switched to a $2 \%$ low serum medium and treated with ( $c$ and d) or without ( $a$ and b) NGF for 3 days. (E) Quantitative analysis of PC12 cells bearing neurites are shown in (D). At least 500 cells were counted for each treatment, and the error bars represent the S.D. of triplicate results. (F) Overexpression of p53(A135V) inhibits NGF-mediated induction of p21 and GAP-43. PC12-HA-p53(A135V)-7 cells were treated as describe in D) and used for Western blot analysis with antibodies against HA, p53, p21, GAP-43, and actin

\section{p53 knockdown markedly inhibits NGF-mediated neurite outgrowth in PC12 cells, which can be rescued by reconstituted p53}

Mutant p53 posseses gain-of-function independent of inhibition of wild-type p53, which may be responsible for inhibiting
NGF-mediated differentiation. To address this, we generated PC12 cell lines in which endogenous p53 was knocked down (p53KD) (Table 1). Two representative clones were presented in Figure $3 A$. Upon NGF treatment, p53 was accumulated in parental, but not p53KD, PC12 cells (Figure 3A). Interestingly, for 3-day treatment with NGF, neurite outgrowth was 
A

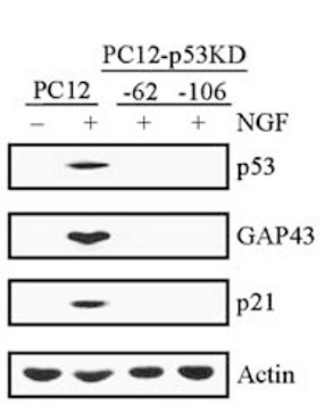

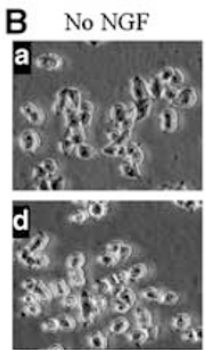
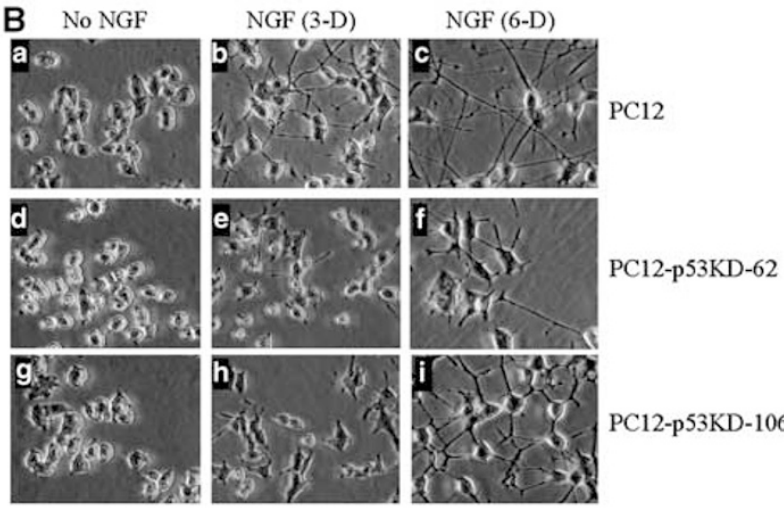

$\mathrm{E}$

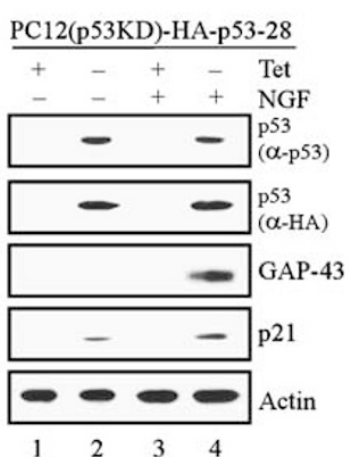

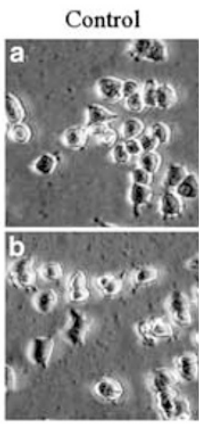
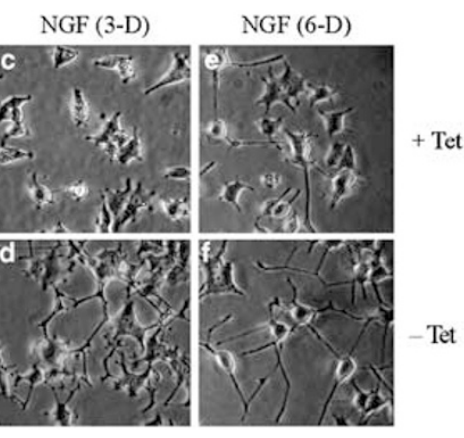
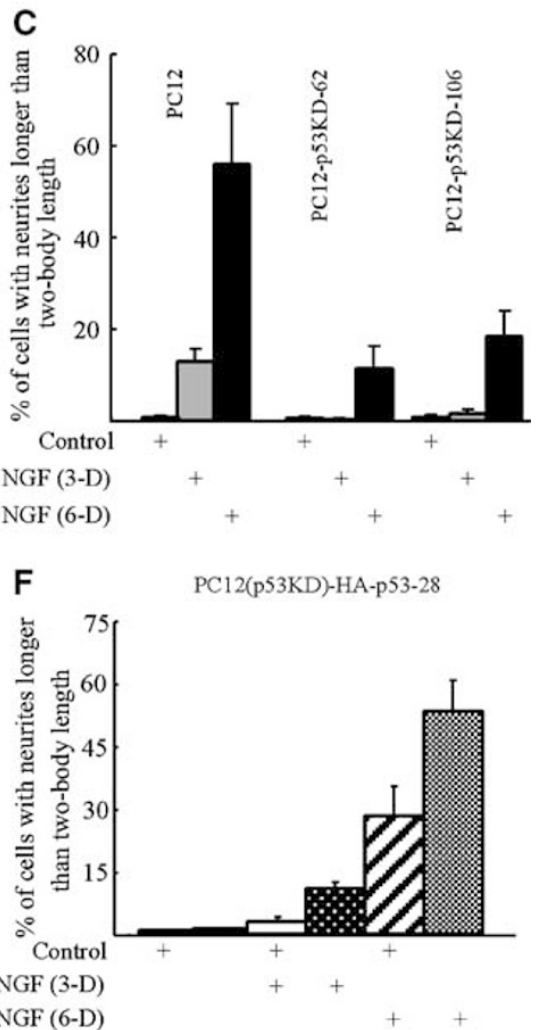

Figure 3 p53 knockdown markedly inhibits NGF-mediated neurites outgrowth, which can be rescued by exogenous p53. (A) p53 knockdown inhibits NGF-mediated induction of p21 and GAP-43. Both parental and p53KD PC12 cells were cultured in a $2 \%$ serum medium with NGF (100 ng/ml) for 3 days. Parental PC12 cells without NGF treatment were used as a control. Cell extracts were collected for Western blot analysis using antibodies against p53, GAP-43, p21, and actin, respectively. (B) Representative microscopy images of both parental and p53KD PC12 cells treated without (a, d, and g), or with NGF for 3 days (b, e, and h) or 6 days (c, f, and i). (C) Quantitative analysis of both parental and p53KD PC12 cells bearing neurites are shown in (B). At least 500 cells were counted for each treatment, and the error bars represent the S.D. of triplicate results. (D) Reconstituted p53 restores the ability of NGF to induce p21 and GAP-43 in p53 knockdown cells. Cells were uninduced or induced to express p53 for $6 \mathrm{~h}$, and then switched to a $2 \%$ FBS medium with or without NGF for 3 days. Cell extracts were collected for Western blot analysis with antibodies against p53, HA, GAP-43, p21, and actin. (E) Representative microscopy images of PC12(p53KD)-HA-p53-28 cells, which were uninduced (a, c, and e) or induced ( $b, d$, and f) to express HA-tagged wild-type murine $p 53$, were mock treated (a and $b$ ) or treated with NGF for 3 days ( $c$ and d) or 6 days (e and f). (F) Quantitative analysis of PC12(p53KD)-HA-p53-28 cells bearing neurites are shown in (E). At least 500 cells were counted for each treatment, and the error bars represent the S.D. of triplicate results

markedly reduced by $\mathrm{p} 53$ knockdown as cells bearing neurites longer than two-body length decreased from 13 to $0-1.5 \%$ (Figure 3B and C). For 6-day treatment with NGF, the reduction by p53 knockdown became profound as cells bearing neurites longer than two-body length decreased from 56.2 to $11.5-18.8 \%$ (Figure 3B and C). Similarly, we found that NGF induction of p21 and GAP-43 was abolished by p53 knockdown (Figure 3A).

To confirm whether $\mathrm{p} 53$ is required, we generated $\mathrm{PC} 12$ cell lines in which endogenous p53 was knocked down and HAtagged wild-type murine p53 is inducibly expressed (Table 1). Multiple clones were selected, and one representative clone, PC12(p53KD)-HA-p53-28, was shown in Figure 3D. Upon NGF treatment, there was no detectable level of endogenous p53 whereas upon induction, exogenous p53 was expressed (Figure 3D, both p53 panels). We showed that exogenous p53 or NGF alone was unable to induce neurite outgrowth in p53KD PC12 cells (Figure 3Eb and c). In addition, p21, but not GAP-43, was induced in a p53-dependent manner (Figure 3D). However, NGF-mediated neurite outgrowth was rescued by exogenous p53 (Figure 3E, compare $c$ and e with $\mathrm{d}$ and $\mathrm{f}$, respectively) as cells bearing neurites longer than twobody length increased from 2.9 to $10.8 \%$ upon 3-day treatment and from 28.1 to $53.2 \%$ upon 6-day treatment (Figure 3F). Likewise, NGF-mediated induction of GAP-43 was also rescued by exogenous p53 (Figure 3D, compare lanes 3-4).

\section{p53 is required for NGF-mediated activation of MAPK and its downstream pathway}

It is well defined that NGF-mediated neurite outgrowth requires sustained activation of the MAPK pathway, including ERK $1 / 2^{18}$ and Egr-1, a downstream target of the MAPK pathway. ${ }^{19}$ This leads us to speculate that the MAPK pathway may not be sufficiently activated in p53KD PC12 cells since they were inert to NGF. We found that upon NGF treatment, phosphorylated ERK1/2 (p-ERK1/2) was accumulated within the first $15 \mathrm{~min}$ and maintained for next $30 \mathrm{~min}$, but the extent 
A

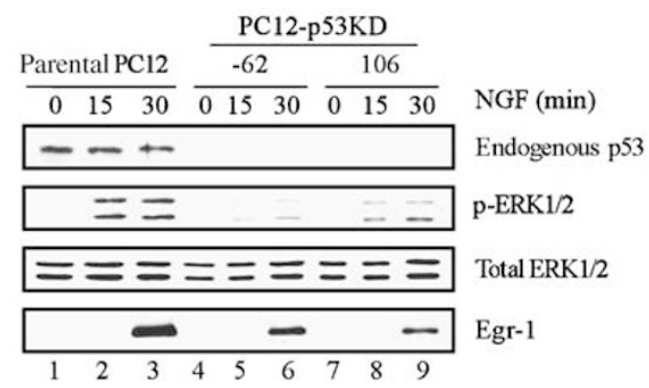

B

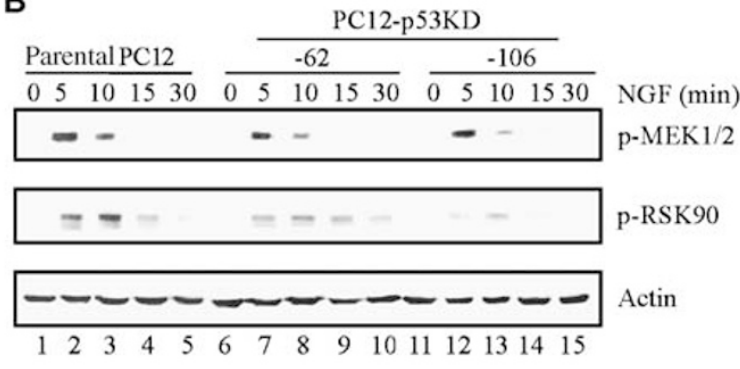

C

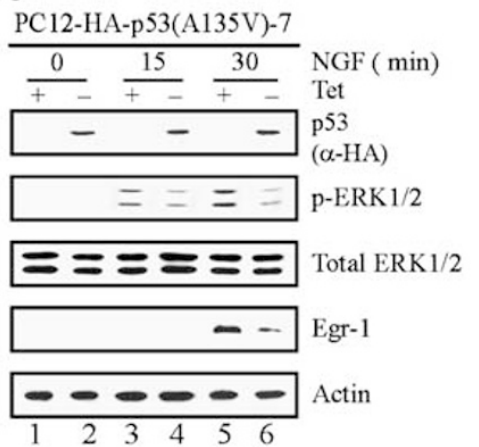

D

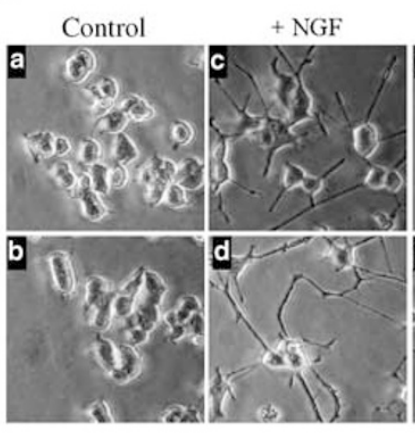

$+\mathrm{NGF}+\mathrm{U} 0126$

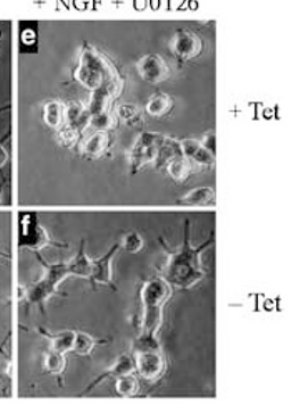

E

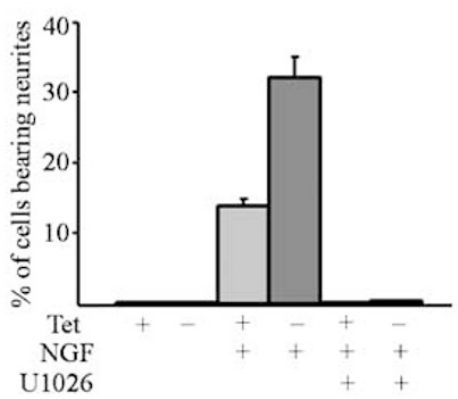

Figure 4 p53 is required for NGF-mediated activation of MAPK and its downstream pathway. (a) NGF-mediated activation of ERK1/2 and Egr- 1 is attenuated in p53KD PC12 cells. Both parental and p53KD PC12 cells were treated with NGF for 0,15 , or 30 min. The level of p53, p-ERK1/2, total ERK1/2, and Egr-1 was analyzed by Western blot analysis with antibodies against p53, p-ERK1/2, total ERK1/2, and Egr-1. (b) NGF-mediated activation of p-MEK1/2 and p-RSK90 is attenuated in p53KD PC12 cells. Both parental and p53 KD PC12 cells were treated with NGF for $0,5,10,15$, or 30 min. The level of p-MEK1/2, p-RSK90, and actin was analyzed using antibodies against p-MEK1/2, p-RSK90, and actin. (c) p53(A135V) attenuates NGF-mediated activation of p-ERK1/2 and Egr-1. PC12 cells were uninduced or induced to express p53(A135V) for $16 \mathrm{~h}$, followed by NGF treatment for 0 , 15, or $30 \mathrm{~min}$. The level of HA-tagged p53, p-ERK1/2, total ERK1/2, Egr-1, and actin was analyzed by Western blot analysis with antibodies against HA, p-ERK1/2, total ERK1/2, Egr-1, and actin. Both total ERK1/2 and actin were used as a loading control. (d) Representative microscopy images of PC12-HA-p53-46 cells uninduced or induced to express p53 for $6 \mathrm{~h}$ and then cultured in the differentiation medium with or without U0126 for 3 days. (e) Quantitative analysis of PC12-HA-p53-46 cells bearing neurites shown in (d). At least 500 cells were counted for each treatment, and the error bars represent the S.D. of triplicate results

of its accumulation was much less in p53KD PC12 cells than in parental cells (Figure $4 a, p-E R K 1 / 2$ panel). Total ERK1/2 protein was quantified as a loading control and found to be comparable (Figure 4a). Likewise, induction of Egr-1 was diminished in p53KD PC12 cells (Figure 4a). We would like to note that upon NGF treatment, the level of p53 was increased within $6 \mathrm{~h}$, but not within $30 \mathrm{~min}$ (Figure 4a). Next, we analyzed the activation of MEK1/2, an upstream kinase of ERK1/2, and RSK90, a downstream substrate of ERK $1 / 2$. $^{2}$ We showed that $\mathrm{p}-\mathrm{MEK} 1 / 2$ was detected within $5 \mathrm{~min}$ and then slowly decreased to the basal level within $30 \mathrm{~min}$ in parental PC12 cells treated with NGF (Figure 4b). Similarly, p-RSK90 was detected within $5 \mathrm{~min}$, peaked at $10 \mathrm{~min}$, and then decreased to the basal level within $30 \mathrm{~min}$ (Figure 4b). In contrast, MEK1/ 2 and RSK90 was only modestly activated in p53KD PC12 cells (Figure $4 b$ ).

In the above, we showed that NGF-mediated neurite outgrowth was inhibited by p53(A135V). Thus, we examined whether the inhibition is preceded by lack of NGF-mediated activation of the MAPK pathway. We found that p53(A135V) substantially attenuated NGF activation of ERK1/2 (Figure 4c). Likewise, NGF induction of Egr-1 was also attenuated by p53(A135V) (Figure 4c).

To determine whether the MAPK pathway is necessary for p53 to enhance NGF-mediated neurite outgrowth, U0126, a specific MEK1/2 kinase inhibitor, was used. We showed that upon treatment with U0126, a significant decrease of NGFmediated neurite outgrowth was observed despite p53 expression (Figure 4d, compare d with f). Most importantly, U0126 completely abolished p53 enhancement of cells bearing neurites longer than two-body length (Figure $4 e$ ).

\section{p53 is essential for NGF-mediated differentiation by inducing TrkA}

While NGF-mediated activation of MAPK is enhanced by p53, it is also dependent on TrkA. Since NGF initiates its signaling pathway through binding to $\operatorname{TrkA}^{2}{ }^{2}$ this suggests that $\mathrm{p53}$ modulates TrkA. To test this, the level of phosphorylated TrkA at tyrosine 490 ( $p$-TrkA-Y490), which correlates with activation of the MAPK pathway, ${ }^{20}$ was determined. As shown in Figure 5a, NGF elicited an increase of $\mathrm{p}-\mathrm{TrkA}-\mathrm{Y} 490$ within $5 \mathrm{~min}$, which was then decreased to the basal level in parental cells. For quantification purpose, we arbitrarily set the level of p-TrkA-Y490 in parental cells at 1 (Figure 5a). Interestingly, we found that $\mathrm{p} 53$ knockdown markedly decreased the level of p-TrkA-Y490 from 1 to 0.17-0.23 (Figure 5a). In addition, upon treatment with NGF, the level of total TrkA protein was slightly increased in parental cells, but much less or no increase in p53KD cells (Figure 5a). Furthermore, the steady-state level of TrkA in parental cells was notably higher than that in p53KD 
a

\begin{tabular}{|c|c|c|c|c|c|c|}
\hline \multirow{2}{*}{\multicolumn{2}{|c|}{ PC12 }} & \multicolumn{4}{|c|}{ PC12-p53KD } & \multirow[b]{3}{*}{ NGF (min) } \\
\hline & & \multicolumn{2}{|r|}{-62} & \multicolumn{2}{|c|}{-106} & \\
\hline 0 & $\begin{array}{lll}5 & 101530\end{array}$ & 05 & $10 \quad 15 \quad 30$ & 05 & $10 \quad 1530$ & \\
\hline & $--=$ & F & & $=$ & & p-TrkA ${ }^{Y} 490$ \\
\hline & 1 & 0.23 & 23 & 0.17 & & \\
\hline- & $-\cdots$ & & $-\quad--$ & & $-\cdots$ & Total TrkA \\
\hline 1 & & 0.14 & & .10 & & \\
\hline
\end{tabular}

b

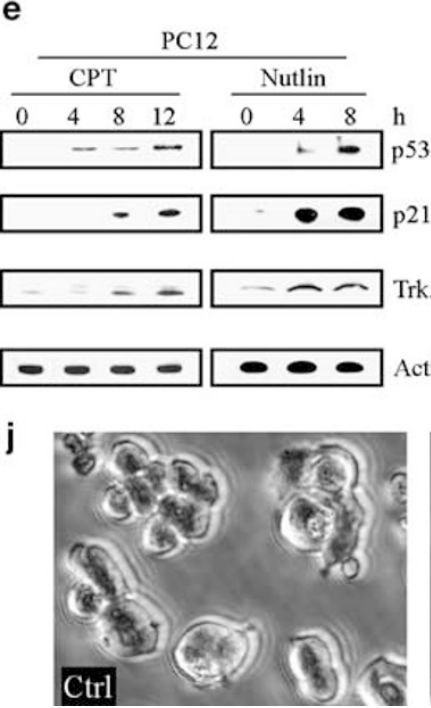

f SH-SY5Y-HA-p53 $\frac{-7}{-+\frac{-9}{-+} \text { Tet }}$

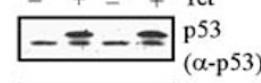

PC12-p53KD PC12 $-62-106$ - $-\pi$ TrkA $\begin{array}{lll}1 & 0.6 & 0.72\end{array}$ $=\mathbf{m}=\mathrm{GAPDH}$ c

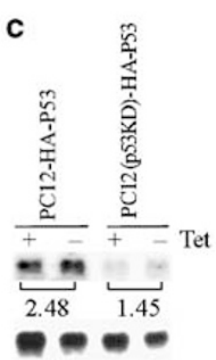

d

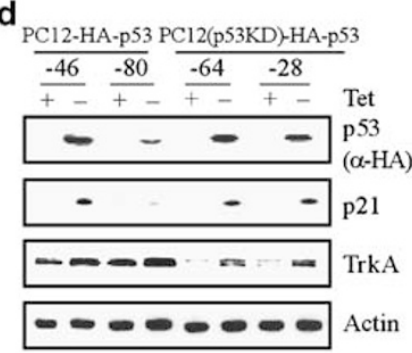

g

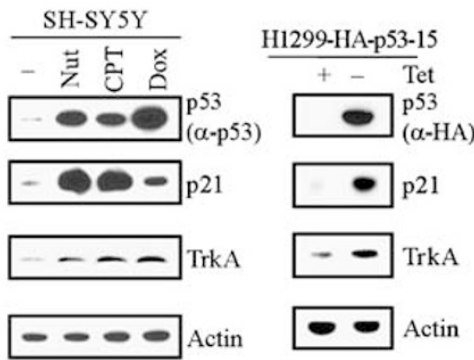

i PC12-HA-p53-46

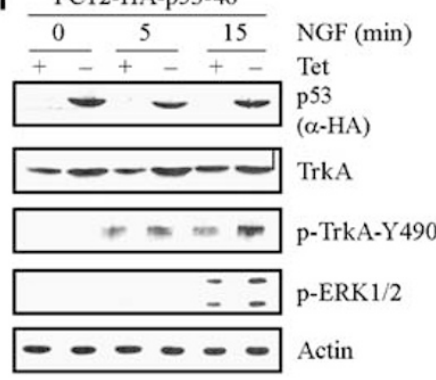

Figure 5 p53 is required for NGF-mediated differentiation by inducing TrkA. (a) The level of total TrkA and p-TrkA-Y490 is reduced in p53KD PC12 cells. Both parental and p53KD PC12 cells were treated with NGF for $0,5,10,15$, or $30 \mathrm{~min}$. The level of p-TrkA-Y490, total TrkA, and actin was analyzed by Western blot analysis with antibodies against $p$-TrkA-Y490, total TrkA, and actin. The relative level of $p-T r k A-Y 490$ in PC12 cells treated with NGF for 5 min was arbitrarily set at 1 . The relative level of total TrkA in untreated PC12 cells was also arbitrarily set at 1 . The effect of p53 knockdown on the level of p-TrkA-Y490 and total TrkA was calculated and shown below the lane. (b) The constitutive level of TrkA mRNA is downregulated in p53KD PC12 cells. A Northern blot was prepared with total mRNA isolated from parental cells and p53KD PC12 cells, and then probed with cDNAs derived from the TrkA and GAPDH genes, respectively. The relative level of TrkA mRNA in parental PC12 cells was arbitrarily set at 1 . The effect of p53 knockdown on the level of TrkA mRNA in p53KD cells was shown below the lane. (c) The level of TrkA mRNA is upregulated upon exogenous p53. The experiment was performed similarly as in (b) using mRNAs isolated from cells uninduced or induced to express exogenous p53 for $5 \mathrm{~h}$. The fold increase of TrkA mRNA by exogenous p53 was shown below the lane. (d) The level of TrkA protein is increased upon induction of exogenous p53 in PC12 and PC12p53KD cells. PC12 and PC12-p53KD cells were uninduced or induced to express exogenous HA-tagged p53 for $6 \mathrm{~h}$ and cell lysates were analyzed by Western blot analysis using antibodies against HA, p21, TrkA, and actin. (e) The level of TrkA protein is increased by endogenous p53 activated by DNA damage or Nutlin in PC12 cells. PC12 cells were treated with either $1 \mu \mathrm{M}$ campotothecin or $0.2 \mathrm{nM}$ Nutlin. At the time point indicated, cell extracts were collected for Western blot analysis with antibodies against p53, p21, TrkA, and actin. (f) The level of TrkA protein is increased upon induction of exogenous p53 in SH-SY5Y. SH-SY5Y cells were uninduced or induced to express p53 for $12 \mathrm{~h}$, and then cell lysates were used for Western blot analysis with antibodies against p53, p21, TrkA, and actin. (g) The level of TrkA protein is increased by endogenous p53 activated by DNA damage or Nutlin in SH-SY5Y cells. SH-SY5Y cells were treated with $0.2 \mathrm{nM} \mathrm{Nutlin,} 0.15 \mathrm{nM}$ campotothecin, $0.25 \mathrm{~g} / \mathrm{ml}$ doxrubicin for $12 \mathrm{~h}$, and then cell extracts were collected for Western blot analysis with antibodies as described in (f). (h) The level of TrkA protein is increased upon induction of exogenous p53 in $\mathrm{H} 1299$ cells. H1299 cells were uninduced or induced to express p53 for $12 \mathrm{~h}$, and then cell lysates were used for Western blot analysis with antibodies against HA, p21, TrkA, and actin. (i) p53 increases NGF-mediated activation of p-TrkA-Y490 and p-ERK1/2. PC12 cells were uninduced or induced to express HA-tagged $p 53$ for $6 \mathrm{~h}$, followed by treatment with NGF for 0,5 , or $15 \mathrm{~min}$. Cell extracts were then collected and analyzed by Western blot analysis with antibodies against HA, total TrkA, p-TrkA-Y490, p-ERK1/2, and actin. (j) Representative microscopy images of PC12 cells mock-treated (Ctr), treated with Nutlin (Nutlin), NGF (NGF), or both Nutlin and NGF (NGF + Nutlin) for 3 days

cells (Figure 5a). Again, if we arbitrarily set the level of TrkA in parental cells at 1 , the steady-state level of TrkA in p53KD cells is low (0.10-0.14) (Figure 5a). These results point to a possibility that p53 may regulate the constitutive level of expression of TrkA. To test this, we performed Northern blot analysis and found that p53 knockdown markedly decreased the constitutive level of TrkA (Figure 5b). Next, we examined whether exogenous p53 is able to induce TrkA and found that p53 increased the level of TrkA mRNA by1.45-fold in PC12 cells without endogenous p53 and 2.48 -fold in those with endogenous p53 (Figure 5c). We also found that the level of TrkA protein was markedly increased upon induction of exogenous p53 in both parental and p53KD cells (Figure 5d).

Next, we determined whether a physiologically relevant level of p53 is capable of regulating TrkA. To do so, we examined the induction of TrkA by endogenous p53 activated by camptothecin, a DNA-damaging agent, or Nutlin, an inhibitor of Mdm2 that can activate p53 without causing DNA damage, ${ }^{21}$ and found that TrkA was induced (Figure 5e). To rule out the possibility that p53 induction of TrkA is cell-type 
specific, we examined the expression of TrkA in human $\mathrm{SH}-\mathrm{SY} 5 Y$ neuroblastoma and $\mathrm{H} 1299$ lung carcinoma cell lines. SH-SY5Y cells have a low level of TrkA expression and therefore are nonresponsive to NGF. ${ }^{22,23}$ Using the tet-on expression system, we generated SH-SY5Y cell lines that are capable of inducibly expressing HA-tagged wild-type p53 (Table 1). Two representative clones, SH-SY5Y-7/-9, were used for further studies. H1299-HA-p53-15, which is capable of inducibly expressing HA-tagged wild-type p53 (Table 1), was also used. We found that TrkA was upregulated by exogenous p53 in SH-SY5Y (Figure 5f) and in $\mathrm{H} 1299$ (Figure $5 \mathrm{~h}$ ) and by endogenous p53 activated by Nutlin or DNA damage agents in SH-SY5Y (Figure $5 \mathrm{~g}$ ). Furthermore, to rule out the possibility that p53 acts nonspecifically to elevate levels of other cell surface receptors, we analyzed the expression level of EGFR and found that p53 had no effect.

To determine the functional significance of TrkA induction by $p 53$, we analyzed the level of $p-T r k A-Y 490$ and $p-E R K 1 / 2$. We showed that upon treatment with NGF, TrkA and ERK1/2 became phosphorylated, which was enhanced by p53 (Figure 5i). We would like to note that TrkA and ERK1/2 were not activated by $\mathrm{p} 53$ in the absence of NGF although the level of TrkA was increased (Figure 5i, compare lanes 1-2). Next, we examined the effect of activated endogenous p53 (via induction of TrkA) on NGF-mediated neurite outgrowth in PC12 cells. We found that NGF-mediated neurite outgrowth was markedly enhanced by endogenous p53 activated by Nutlin (Figure 5j).

\section{TrkA is a direct target gene of p53}

To test whether p53 directly induces TrkA, a DNA fragment spanning TrkA promoter from nt -1706 to +32 was amplified from the rat genome using PCR. This TrkA promoter and its derivatives, which contain Sp1-like GC-rich elements and/or two potential p53-responsive elements, were then cloned for luciferase assay (Figure 6a). We showed that the TrkA promoter from nt -1706 to +32 led to a 3.5-fold increase of luciferase activity by wild-type p53 but not p53(A135V) whereas the promoter from nt -1033 to +32 lost its activity (Figure 6a). This suggests that the GC-rich elements but not the potential p53-responsive elements are required. As a

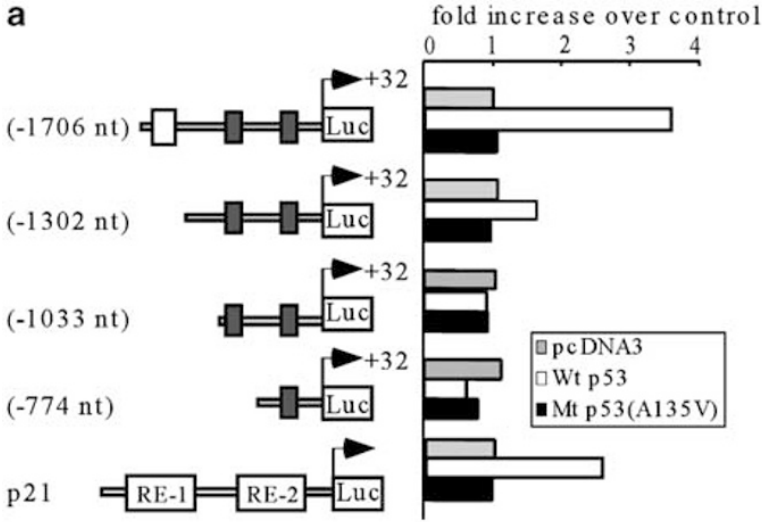

b

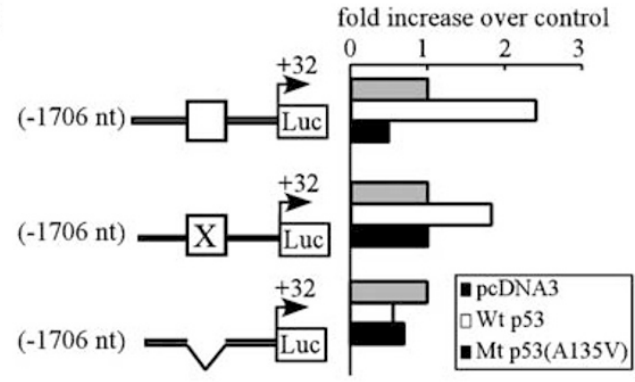

GC-rich element $\mathrm{X}$ Point mutation at c

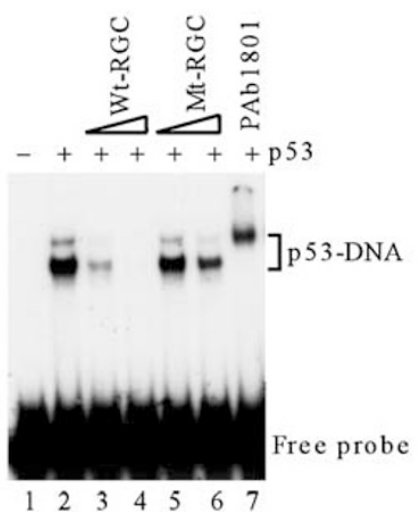

e

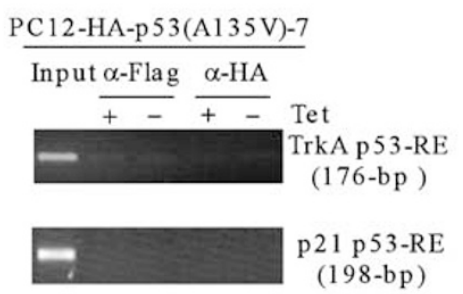

d

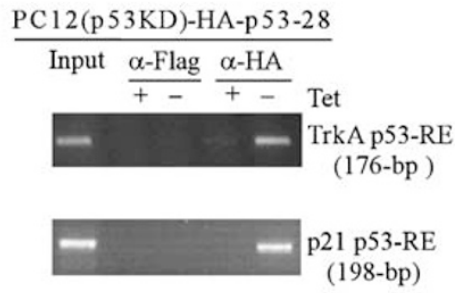

f

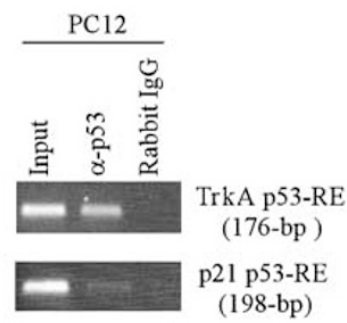

Figure 6 TrkA is a direct target gene of p53. (a) The TrkA promoter is responsive to wild-type p53. Dual luciferase assay was performed as described in Materials and Methods. The fold increase in relative luciferase activity for each construct was calculated using an empty pcDNA3 vector as a control. (b) The GC-rich elements are responsible for p53 activation of the TrkA promoter. Constructs that contain point mutations in the GC-rich elements or a deletion of the GC-rich elements were generated as described in Materials and Methods. (c) p53 binds to the GC-rich elements in the TrkA promoter. Gel shift analysis was performed with a 176-bp DNA fragment containing the GC-rich elements in the TrkA promoter. The p53-DNA complex was resolved in 4\% polyacrylamide gel. For competition assays, unlabeled wild-type RGC ( 20 and $100 \mathrm{ng}$ ) or mutant RGC ( 20 and $100 \mathrm{ng}$ ) were added to the reaction run in lanes 3-4 and 5-6, respectively. For 'supershifting' the p53-DNA complex, $1 \mu \mathrm{g}$ of antip53 monoclonal antibody Pab1801 was added in the reaction run in lane 7. (d-e) Wild-type p53 (d) but not mutant p53 (e), binds to the TrkA and p21 promoters in vivo. ChIP assays were performed as described in Materials and Methods. Anti-HA antibody was used to immunoprecipitate p53-DNA complexes. Anti-Flag antibody was used as a control. (f) The TrkA promoter is bound by endogenous p53 at a nonstressed condition. ChIP assays were performed as described in Materials and Methods. Rabbit anti-p53 antibody was used to immunoprecipitate p53-DNA complexes. Rabbit IgG was used as a control 
control, the p21 promoter led to 2.5-fold increase of luciferase activity by wild-type p53 (Figure 6a). Previously, GC-rich elements were shown to be responsive to p53. ${ }^{24}$ To test this, we made point mutations or a deletion in the GC-rich elements and found that the deletion or point mutations led to complete or partial inactivation of the TrkA promoter (Figure 6b).

To demonstrate that p53 directly binds to the GC-rich elements, we performed DNA gel shift assay with ${ }^{32} \mathrm{P}$-labeled 176-bp DNA fragment spanning the region of the GC-rich elements in the TrkA promoter (Figure 6c). We found that when the recombinant p53 protein was mixed with the DNA fragment, a complex was detected, presumably containing both $\mathrm{p} 53$ and the ${ }^{32} \mathrm{P}$-labeled DNA, which was not detected in the absence of p53 protein. Moreover, we showed that the level of the p53-DNA complex was reduced in a dosagedependent manner by an excess amount of unlabeled DNA fragment containing a p53-binding site from the ribosomal gene cluster (Wt-RGC) but not the one containing a mutant p53-binding site (Mt-RGC). Furthermore, we showed that upon addition of anti-p53 to the mixture of p53 and DNA, the complex was 'supershifted.'

To further demonstrate the involvement of the GC-rich elements, chromatin immunoprecipitaion (ChIP) was performed with primers to amplify a fragment in the TrkA and p21 promoters. Anti-HA was used to bring down p53-DNA complexes. Anti-Flag antibody was used as a control. We showed that the fragment containing the GC-rich elements was enriched in anti-HA (i.e. p53 containing), but not in antiFlag, immunocomplexes (Figure 6d). Similarly, the p21 promoter was immunoprecipitated with p53 (Figure 6d). We also showed that p53(A135V) was unable to bind to the TrkA or p21 promoter (Figure 6e). Furthermore, we found that at the nonstressed condition, the TrkA promoter was bound by endogenous p53 whereas little p53 bound to the p21 promoter (Figure 6f), consistent with the above observation that the basal level of p53 is necessary for the constitutive level of TrkA expression.

\section{Discussion}

In this study, we provided evidence that p53 is required for NGF-mediated neuronal differentiation in PC12 cells. We found that p53 is required for NGF-mediated activation of the MAPK pathway. Most importantly, we found that the constitutive level of endogenous p53 is necessary for sustained expression of the constitutive level of TrkA. In addition, when activated by NGF or other stimuli, p53 is able to further induce the expression of TrkA. Moreover, induction of TrkA by activated endogenous wild-type p53 enhances neurite outgrowth mediated by NGF. Interestingly, p53 alone is not sufficient to activate the signaling pathways of TrkA and MAPK. Taken together, our data indicate that when PC12 cells with endogenous p53 are exposed to NGF, p53 is activated and then directly induces the expression of TrkA, which in turn provides more binding partners for NGF, amplifying the level of activation of TrkA and subsequently, the signaling pathway for neuronal differentiation. However, in PC12 cells wherein endogenous p53 is knocked down or inhibited by mutant p53, the constitutive level of expression of
TrkA is substantially reduced. In addition, the amplifying cycle of the activation of TrkA by NGF via p53 is broken down. As a result, upon exposure to NGF, the signaling pathway leading to neuronal differentiation may be weakly activated, but is not strong enough to elicit neurite outgrowth. It should be noted that the extent of attenuation in neurite outgorwth by $\mathrm{p} 53(\mathrm{~A} 135 \mathrm{~V})$ is less than that by $\mathrm{p} 53$ knockdown, especially during a extended treatment (6 days) with NGF. One possibility is that $\mathrm{p53}(\mathrm{A} 135 \mathrm{~V})$ may posses some activity since it is a temperature-sensitive mutant. ${ }^{17}$ The other possibility is that when both mutant and wild-type p53 are expressed in the same cell, there is always a fraction of active wild-type p53 homotetramer (up to $25 \%$ ). This may explain why mutant p53 cannot totally, and in some case, may not be able to, inhibit NGF-mediated neurite outgrowth. ${ }^{13}$ Our data are consistent with earlier reports that reconstituted TrkA can restore the response to NGF for PC12 cells deficient in TrkA ${ }^{25}$ and overexpression of TrkA can further accelerate NGF-mediated neuronal differentiation. ${ }^{26}$ Based on these findings, a model for the role of p53 in neuronal differentiation is presented in Figure 7.

It is well known that upon NGF treatment, neuronal cells are permanently arrested and undergo neurite outgrowth. Thus, cell cycle arrest and neurite outgrowth are two critical events for neuronal differentiation. ${ }^{2}$ Our results indicated that p53 regulates both events through induction of p21 and GAP-43. We showed that p53 knockdown and p53(A135V) impair NGF-mediated induction of p21 whereas reconstituted p53 in p53KD PC12 cells restores it. These results are consistent with a previous report that p53 plays a role in NGF-mediated differentiation by inducing cell cycle arrest. ${ }^{13}$ Interestingly, although p53 alone induces p21 expression, this induction is not sufficient to promote neurite outgrowth in the absence of NGF, suggesting that other NGF-mediated activities are also required. Unlike the induction of p21, p53 alone is not sufficient, but required for, NGF to induce GAP-43. Since

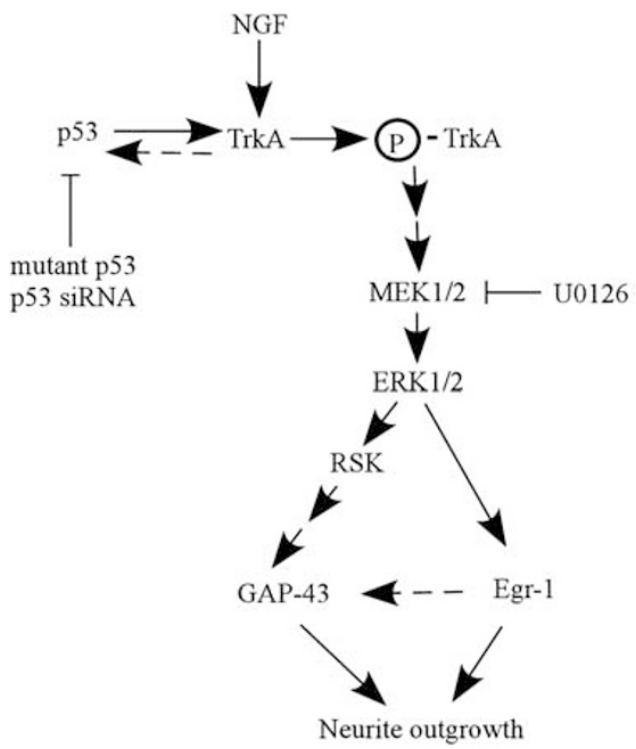

Figure 7 A model of p53 for neurite outgrowth in PC12 cells 
the increased expression of GAP-43 by NGF is due to stabilization of GAP-43 mRNA, ${ }^{27}$ it is likely that p53 may modulate the expression of GAP-43 indirectly by regulating other neuronal differentiation-related genes, including TrkA.

TrkA is shown to be required for cell survival during differentiation and for cell death during neurotrophin deficiency. ${ }^{28,29}$ Thus, p53 induction of TrkA may impinge on other pathways. Indeed, a recent study showed that apoptosis induced by TrkA in neuroblastoma is p53 dependent. ${ }^{30}$ This may explain why the level of TrkA, which correlates with spontaneous regression of neuroblastoma, is scored as a favorable prognosis marker. ${ }^{31}$ On the other hand, considering the fact that TrkA is crucial for the development of sympathetic neuron, ${ }^{32}$ one may argue how p53-null mice, which are deficient in p53 and consequently, may be low in TrkA, develop normally. ${ }^{33}$ This does not necessarily contradict the observations in this study. Upon further examination, a small, but detectable number of p53-null mice have defects in neural tube closure, especially in female embryos. ${ }^{9,34}$ In addition, p53 is not the only regulator of TrkA. We showed that p53 knockdown leads to $\sim 30-40 \%$ reduction of the constitutive level of TrkA. Thus, a 'backup' gene, such as other p53 family members that are capable of inducing some p53 target genes, ${ }^{4}$ may compensate for the loss of TrkA expression in the absence of $p 53$.

\section{Materials and Methods}

\section{Materials}

PC12 Tet-off cells, which are capable of expressing Tet-VP16 for the tetracycline-repressible expression system, were purchased from Clontech (cat. No. 630906). SH-SY5Y cell line (cat \#CRL-2266) was purchased from ATCC. The dual-luciferase assay kit and NGF (murine, $2.5 \mathrm{~s}$ ) were purchased from Promega. Antibodies against p21, Egr-1, and TrkA were purchased from Santa Cruz Biotechnology. Anti-HA antibody was purchased from Covance. Anti-p-TrkA-Y490, anti-p-ERK1/2, antip-MEK1/2, anti-p-RSK90, and MEK1/2 kinase inhibitor U0126 were purchased from Cell Signaling. Anti-actin and anti-GAP-43 were purchased from Sigma. Anti-ERK1 was purchased from BD Biosciences.

\section{Plasmids and mutagenesis}

To generate constructs for the tetracycline-repressible (tet-off) expression system, HA-tagged wild-type and mutant murine p53 were cloned into a tetracycline-repressible expression vector, pUHD 10-3, at its EcoRI site. To generate constructs for the tetracycline-inducible (tet-on) expression system, HA-tagged wild-type human p53 was cloned into a tetracyclineinducible expression vector, pcDNA4, at its EcoRI site (pcDNA4-HA-p53). To generate constructs for luciferase assay, wild-type and mutant murine p53 were cloned into pcDNA3. To generate constructs expressing small interference RNAs (siRNAs) targeting the rat $p 53$ coding region, a region of 19 nucleotides in the rat p53 gene (GAG CAT TGC CCG GAG CTG C or GACTCC AGT GGG AAT CTT C) was selected for synthesis, which were then cloned into a puromycin-selectable siRNA expression vector under the control of the U6 promoter (pBabe-U6) and the resulting plasmid was designated as pBabe-U6-si-p53. To generate the luciferase reporter under the control of the TrkA promoter (pGL2/-1706 TrkA), a 1738-bp DNA fragment containing the TrkA promoter was amplified from genomic DNA purified from PC12 cells using a upstream primer, 5'-CTG CAG AAC TCA
CGC CCT GTA ATG-3', and a downstream primer, 5'-AAG CTT GCT TGG CTG CTG TAG GA-3'. The DNA fragment was confirmed by sequencing and then cloned into pGL2-basic vector at Smal and Hindll sites to generate the $p G L 2 /-1706$ TrkA vector. To generate the luciferase reporter, pGL2/-1302 TrkA, a Sacl-Hindlll fragment obtained from the pGL2/-1706 TrkA was cloned into pGL2-Basic. To generate the luciferase reporter, pGL2/-1033 TrkA, an Xhol-Hindll fragment from the pGL2/1302 TrkA was cloned into $p G L 2-B a s i c$. To generat the luciferase reporter, pGL2/-774 TrkA, a Bgll-Hindll fragment from the pGL2/-1033 TrkA vector was cloned into pGL2-Basic. Constructs containing either point mutations or deletion in the TrkA promoter were generated using PCRbased mutagenesis and confirmed by sequencing. Briefly, two PCR reactions were performed using pGL2/-1706 TrkA as a template: one with an upstream primer P1 ( $5^{\prime}$-cct cct ggg ctt tca gac ttc t-3') and a specific downstream primer (see below for details); and other with a specific upstream primer (see below for details) and a downstream primer P2 (5'cct cag ttg aca ggc taa ata-3'). Next, these two PCR products were mixed and used as a template for the third PCR reaction using primers $P 1$ and $P 2$. The PCR products were then used to replace the corresponding region in the TrkA promoter at the Rsill and Sacll sites. Specifically, to generate the TrkA promoter with point mutations in the GC-rich elements, the specific downstream primer was P3 ( $5^{\prime}$-ttg aca ggc taa ata ttt tcc ctt gac ttg gtg gga ggg gcg gag aga aca gag aagt- $\left.3^{\prime}\right)$ whereas the specific upstream primer was P4 (5'-GCT TAG GCC CTT TCC AGA AAC AGA TTG GTT TAC GCC ACC GAC TTC TCT GTT CTC TCt atc CC-3'). To generate the TrkA promoter with deletion of the GC-rich elements, the specific downstream primer was P5 (5'-CTG GTG GGA GAG TGG GGC$\left.3^{\prime}\right)$ whereas the specific upstream primer was P6 (5'-gcc cca ctc tcc cac cag-3').

\section{Cell culture}

The PC12 tet-off cells were maintained in Ham's F12 medium supplemented with $15 \%$ horse serum and $2.5 \%$ fetal bovine serum (FBS) as suggested by ATCC. SH-SY5Y tet-on cells were cultured in 1:1 mixture of Eagle's medium and Ham's F12 medium with $10 \%$ tetracycline approved FBS as suggested by ATCC. $\mathrm{H} 1299$ tet-off cells were cultured in DMEM with $10 \%$ FBS. Selection drugs were added to the medium as needed. Cells were grown at $37^{\circ} \mathrm{C}$ with $5 \% \mathrm{CO}_{2}$ whereas mutant p53 inducible $\mathrm{PC} 12$ cells were cultured at $38.5^{\circ} \mathrm{C}$. All inductions were performed in culture medium with either $10 \%$ tet-system-approved serum (for tet-off system) or $10 \%$ regular FBS plus $2 \mu \mathrm{g} / \mathrm{ml}$ tetracycline (for tet-on system). For NGF treatment, cells were uninduced or induced to express protein of interest and then switched to a medium containing $2 \%$ tetracycline-approved FBS plus NGF. For treatment with both NGF and U0126, cells were pretreated with $10 \mu \mathrm{M}$ of $\mathrm{U} 0126$ for $2 \mathrm{~h}$ before adding NGF. The concentration of NGF used for all the experiments was $100 \mathrm{ng} /$ $\mathrm{ml}$ if not specified.

\section{Establishment of stable cell lines}

All transfections were achieved using Lipofectamine 2000 according to the manufacturer's instructions (Invitrogen). For generation of wild-type or mutant p53-inducible cell lines, parental PC12 tet-off cells were cotransfected with a pUHD10-3 vector, which expresses either wild-type or mutant $\mathrm{p53}$, and $\mathrm{pBabe}$ vector, which expresses the puromycin-resistant gene for clone selection. Cells were selected with $1 \mu \mathrm{g} / \mathrm{ml}$ of puromycin and $100 \mu \mathrm{g} / \mathrm{ml}$ of G418 for 4 weeks. Individual clones were screened for inducible expression of $\mathrm{p} 53$ by Western blot analysis. For generation of p53KD PC12 cell lines, PC12 cells were transfected with pBabe-U6-si-p53 
and selected with puromycin for 4 weeks. Individual clones were screened for lack of accumulation of endogenous p53 upon NGF treatment by Western blot analysis. For generation of PC12 cell lines in which endogenous rat p53 is knocked down and an exogenous murine p53 is inducibly expressed, pBabe-U6-si-p53 and pUHD10-3 vector-expressing wild-type murine p53 were co-transfected into PC12 cells. After transfection, cells were selected with $1 \mu \mathrm{g} / \mathrm{ml}$ of puromycin and $100 \mu \mathrm{g} /$ $\mathrm{ml}$ of G418 for 4 weeks. Individual clones were screened for inducible expression of p53 or lack of accumulation of endogenous p53 upon NGF treatment by Western blot analysis. To generate SH-SY5Y tetracyclineinducible (tet-on) cell lines, SH-SY5Y cells were transfected with pcDNA6 (Invitrogen), which encodes a tetracycline repressor, and selected with $7.5 \mu \mathrm{g} / \mathrm{ml}$ of blasticidine for 8 weeks. Multiple clones that can express the tetracycline repressor were selected and used for subsequent transfection with pcDNA4-HA-p53 plasmid. After selection with $100 \mu \mathrm{g} / \mathrm{ml}$ of zeocin for 8 weeks, individual clones were screened for inducible expression of p53 by Western blot analysis.

\section{Growth rate analysis}

To determine the rate of cell growth, $5 \times 10^{4} \mathrm{PC} 12$ cells were seeded per $60-\mathrm{mm}$ diameter plate. Cells were uninduced or induced to express the protein of interest in the presence or absence of tetracycline $(2 \mu \mathrm{g} / \mathrm{ml})$. Culture media were replaced every $72 \mathrm{~h}$. Each day over a 5-day period, three plates for each group were rinsed twice with PBS to remove dead cells. Live cells on the plates were trypsinized and samples from each plate were counted three times using a Coulter cell counter (Coulter Corporation, Miami, FL, USA). The average number of cells from each group was used for growth rate determination.

\section{DNA histogram analysis}

Cells were seeded at $2 \times 10^{5}$ per 90 -mm-diameter plate and uninduced or induced to express p53 in the presence or absence of tetracycline $(2 \mu \mathrm{g} /$ $\mathrm{ml})$. At $72 \mathrm{~h}$ after induction, both floating and dead cells in the media and live cells on the plate were collected and fixed with $10 \mathrm{ml}$ of $75 \%$ ethanol overnight and then centrifuged and resuspended in $300 \mu$ l of PBS solution containing $50 \mu \mathrm{g} / \mathrm{ml}$ each of RNase A (Sigma) and propidium iodide (Sigma). The stained cells were analyzed in a fluorescence-activated cell sorter (FACS Calibur; Becton Dickinson) within $4 \mathrm{~h}$. The percentage of cells in the sub-G1, G1, S, and G2/M phases was determined by the Cell Quest program.

\section{Neurite outgrowth assay}

Cells $\left(5 \times 10^{4}\right)$ were plated in each well of the six-well plate. Cells were uninduced or induced as needed. After induction, culture medium was changed to a differentiation medium ( $2 \%$ tet-system-approved FBS and $100 \mathrm{ng} / \mathrm{ml} \mathrm{NGF}$ ) and replaced every 2 days. Cells with at least one neurite longer than two-body length were counted as neurite positive. At least 500 cells were counted for each group performed in triplicate.

\section{Western blot analysis}

Cells were washed and collected from plates in PBS solution, resuspended with $2 \times$ sample buffer, and boiled for $5 \mathrm{~min}$. Proteins were then resolved in an $8 \%$ SDS-PAGE gel and transferred to a nitrocellulose membrane.

\section{RNA isolation and Northern blot analysis}

Total RNA was isolated using Trizol reagent (Invitrogen) and used for Northern blot analysis. The TrkA probe was made from a 650-bp cDNA fragment amplified by RT-PCR with an upstream primer (5'-ATG AGA CCA GCT TCA TC-3') and a downstream primer (5'-GCT CCC ACTT GAG AAT G-3'). The glyceraldehyde-3-phosphate dehydrogenase probe was made as described. ${ }^{35}$

\section{Luciferase assay}

The dual-luciferase assay was carried out as previously reported. ${ }^{35} \mathrm{~A}$ luciferase reporter $(300 \mathrm{ng})$ along with pcDNA3 or pcDNA3 that expresses wild-type or mutant p53 (300 ng) was transfected into PC12 cells plated in a 24-well plate. All experiments were performed in triplicate.

\section{Gel-shift assay}

The assay was carried out as described. ${ }^{36}$ Specifically, a 176-bp fragment containing the GC-rich elements was amplified by PCR using pGL2/-1706 TrkA as template with $5^{\prime}$ primer, TrkA-RE-5 (5'-CTC CTG GGC TTT CAG ACT TC-3'), and $3^{\prime}$ primer, TrkA-RE-3 (5'-CCC TAG TTG ACA GGC TAA ATA $\left.-3^{\prime}\right)$. The fragment was labeled with ${ }^{32} \mathrm{P}$. Approximately $1 \mathrm{ng}$ of the labeled probe DNA and $20 \mathrm{ng}$ p53 protein were added to a mixture of $20 \mathrm{mM}$ HEPES, pH 7.9, $25 \mathrm{mM} \mathrm{KCl}, 0.1 \mathrm{mM}$ EDTA, 10\% glycerol, $2 \mathrm{mM}$ $\mathrm{MgCl}_{2}, 2 \mathrm{mM}$ spermidine, $0.5 \mathrm{mM}$ DTT, $0.025 \%$ NP-40, $100 \mathrm{ng}$ doublestraded poly(dG:dC), and $2 \mu \mathrm{g} \mathrm{BSA}$. The $\mathrm{p} 53$ protein was expressed in a baculovirus expression system and affinity purified using anti-p53 monoclonal antibody PAb421. The p53-responsive element in the ribosomal gene cluster (RGC) was used as a competitor. ${ }^{37}$ The wildtype and mutant RGC-containing double-stranded oligonucleotides for competition were as described. ${ }^{38}$

\section{ChIP assay}

ChIP was performed as described. ${ }^{35}$ The primers used to detect the TrkA promoter were: TrkA-RE-5 (5'-CTC CTG GGC TTT CAG ACT TC- $\left.3^{\prime}\right)$ and TrkA-RE-3 (5'-CCC TAG TTG ACA GGC TAA ATA-3'). The primers used to detect the p21 promoter were: p21-RE-5 (5'-Gcc tcc tga gtg ctg gg-3') and p21-RE-3 (5'-AGG GTG GGG GGT GGT AT-3').

\section{Acknowledgements}

We thank Anita Chen for technical assistance. This work was supported in part by NIH Grants (CA076069 and CA081237).

\section{References}

1. Wallingford JB, Seufert DW, Virta VC and Vize PD (1997) p53 activity is essential for normal development in Xenopus. Curr. Biol. 7: 747-757.

2. Huang EJ and Reichardt LF (2003) Trk receptors: roles in neuronal signal transduction. Annu. Rev. Biochem. 72: 609-642.

3. Tischler AS and Greene LA (1975) Nerve growth factor-induced process formation by cultured rat pheochromocytoma cells. Nature 258: 341-342.

4. Harms K, Nozell S and Chen X (2004) The common and distinct target genes of the p53 family transcription factors. Cell Mol. Life Sci. 61: 822-842.

5. Ko LJ and Prives C (1996) p53: puzzle and paradigm. Genes Dev. 10: 1054-1072

6. Levine AJ (1997) p53, the cellular gatekeeper for growth and division. Cell 88: 323-331. 
7. Abarzua P, LoSardo JE, Gubler ML and Neri A (1995) Microinjection of monoclonal antibody PAb421 into human SW480 colorectal carcinoma cells restores the transcription activation function to mutant p53. Cancer Res. 55: 3490-3494.

8. Miller FD, Pozniak CD and Walsh GS (2000) Neuronal life and death: an essential role for the p53 family. Cell Death Differ. 7: 880-888.

9. Sah VP, Attardi LD, Mulligan GJ, Williams BO, Bronson RT and Jacks T (1995) A subset of p53-deficient embryos exhibit exencephaly. Nat. Genet. 10: 175-180.

10. Eizenberg O, Faber-Elman A, Gottlieb E, Oren M, Rotter V and Schwartz M (1996) p53 plays a regulatory role in differentiation and apoptosis of central nervous system-associated cells. Mol. Cell Biol. 16: 5178-5185.

11. Komarova EA, Chernov MV, Franks R, Wang K, Armin G, Zelnick CR, Chin DM, Bacus SS, Stark GR and Gudkov AV (1997) Transgenic mice with p53responsive lacZ: p53 activity varies dramatically during normal development and determines radiation and drug sensitivity in vivo. EMBO J. 16: 1391-1400.

12. Tokumoto YM, Tang DG and Raff MC (2001) Two molecularly distinct intracellular pathways to oligodendrocyte differentiation: role of a p53 family protein. EMBO J. 20: 5261-5268.

13. Hughes AL, Gollapudi L, Sladek TL and Neet KE (2000) Mediation of nerve growth factor-driven cell cycle arrest in PC12 cells by p53. Simultaneous differentiation and proliferation subsequent to p53 functional inactivation. J. Biol. Chem. 275: 37829-37837.

14. Ferreira A and Kosik KS (1996) Accelerated neuronal differentiation induced by p53 suppression. J. Cell Sci. 109 (Part 6): 1509-1516.

15. Gollapudi L and Neet KE (1997) Different mechanisms for inhibition of cell proliferation via cell cycle proteins in PC12 cells by nerve growth factor and staurosporine. J. Neurosci. Res. 49: 461-474.

16. Schrama LH, Lepperdinger G, Moritz A, van den Engel NK, Marquart A Oestreicher AB, Eggen BJ, Hage WJ, Richter K and Destree OH (1997) B-50/ growth-associated protein-43, a marker of neural development in Xenopus laevis. Neuroscience 76: 635-652.

17. Michalovitz D, Halevy $O$ and Oren M (1990) Conditional inhibition of transformation and of cell proliferation by a temperature-sensitive mutant of p53. Cell 62: 671-680.

18. Qui MS and Green SH (1992) PC12 cell neuronal differentiation is associated with prolonged p21ras activity and consequent prolonged ERK activity. Neuron 9: 705-717

19. Levkovitz Y, O'Donovan KJ and Baraban JM (2001) Blockade of NGF-induced neurite outgrowth by a dominant-negative inhibitor of the egr family of transcription regulatory factors. J. Neurosci. 21: 45-52.

20. Obermeier A, Lammers R, Wiesmuller KH, Jung G, Schlessinger J and Ullrich A (1993) Identification of Trk binding sites for SHC and phosphatidylinositol $3^{\prime}$-kinase and formation of a multimeric signaling complex. J. Biol. Chem. 268: 22963-22966.

21. Vassilev LT, Vu BT, Graves B, Carvajal D, Podlaski F, Filipovic Z, Kong N, Kammlott U, Lukacs C, Klein C, Fotouhi N and Liu EA (2004) In vivo activation of the p53 pathway by small-molecule antagonists of MDM2. Science 303: 844-848.

22. Lavenius E, Gestblom C, Johansson I, Nanberg E and Pahlman S (1995) Transfection of TRK-A into human neuroblastoma cells restores their ability to differentiate in response to nerve growth factor. Cell Growth Differ. 6 : 727-736.

23. Poluha W, Poluha DK and Ross AH (1995) TrkA neurogenic receptor regulates differentiation of neuroblastoma cells. Oncogene 10: 185-189.

24. Bargonetti J, Friedman PN, Kern SE, Vogelstein B and Prives C (1991) Wildtype but not mutant $p 53$ immunopurified proteins bind to sequences adjacent to the SV40 origin of replication. Cell 65: 1083-1091.

25. Loeb DM, Maragos J, Martin-Zanca D, Chao MV, Parada LF and Greene LA (1991) The trk proto-oncogene rescues NGF responsiveness in mutant NGFnonresponsive PC12 cell lines. Cell 66: 961-966.

26. Hempstead BL, Rabin SJ, Kaplan L, Reid S, Parada LF and Kaplan DR (1992) Overexpression of the trk tyrosine kinase rapidly accelerates nerve growth factor-induced differentiation. Neuron 9: 883-896.

27. Mobarak $C D$, and erson KD, Morin M, Beckel-Mitchener A, Rogers SL Furneaux H, King P and Perrone-Bizzozero NI (2000) The RNA-binding protein HuD is required for GAP-43 mRNA stability, GAP-43 gene expression, and PKC-dependent neurite outgrowth in PC12 cells. Mol. Biol. Cell. 11: 3191-3203.

28. Kaplan DR and Miller FD (1997) Signal transduction by the neurotrophin receptors. Curr. Opin. Cell Biol. 9: 213-221.

29. Yan C, Liang Y, Nyland er KD and Schor NF (2002) TrkA as a life and death receptor: receptor dose as a mediator of function. Cancer Res. 62 : 4867-4875

30. Lavoie JF, Lesauteur L, Kohn J, Wong J, Furtoss O, Thiele CJ, Miller FD and Kaplan DR (2005) TrkA induces apoptosis of neuroblastoma cells and does so via a p53-dependent mechanism. J. Biol. Chem. 280: 29199-29207.

31. Nakagawara A, Arima-Nakagawara M, Scavarda NJ, Azar CG, Cantor AB and Brodeur GM (1993) Association between high levels of expression of the TRK gene and favorable outcome in human neuroblastoma. N. Engl. J. Med. 328: $847-854$.

32. Smeyne RJ, Klein R, Schnapp A, Long LK, Bryant S, Lewin A, Lira SA and Barbacid M (1994) Severe sensory and sympathetic neuropathies in mice carrying a disrupted Trk/NGF receptor gene. Nature 368: 246-249.

33. Donehower LA, Harvey M, Slagle BL, McArthur MJ, Montgomery Jr CA, Bute JS and Bradley A (1992) Mice deficient for p53 are developmentally normal but susceptible to spontaneous tumours. Nature 356: 215-221.

34. Armstrong JF, Kaufman MH, Harrison DJ and Clarke AR (1995) Highfrequency developmental abnormalities in p53-deficient mice. Curr. Biol. 5 : 931-936.

35. Harms $\mathrm{KL}$ and Chen $\mathrm{X}(2005)$ The $\mathrm{C}$ terminus of $\mathrm{p53}$ family proteins is a cell fate determinant. Mol. Cell Biol. 25: 2014-2030.

36. Chen X, Farmer G, Zhu H, Prywes R and Prives C (1993) Cooperative DNA binding of p53 with TFIID (TBP): a possible mechanism for transcriptional activation [published erratum appears in Genes Dev 1993 Dec;7(12B):2652] Genes Dev. 7: 1837-1849.

37. Kern SE, Kinzler KW, Bruskin A, Jarosz D, Friedman $P$, Prives $C$ and Vogelstein B (1991) Identification of p53 as a sequence-specific DNA-binding protein. Science 252: 1708-1711.

38. Bargonetti J, Reynisdottir I, Friedman PN and Prives C (1992) Site-specific binding of wild-type p53 to cellular DNA is inhibited by SV40T antigen and mutant p53. Genes Dev. 6: 1886-1898. 